$\xi=$ 잘

\title{
Temporomandibular joint disorders - a lookback in time
}

\author{
Nazish Baig ${ }^{1}$, Nikita Parasrampuria ${ }^{2 *}$, Babita Yeshwante ${ }^{3}$, Debojyoti Mazumdar ${ }^{4}$ \\ ${ }^{1}$ MDS ,Professor, Department of Prosthodontics and Crown \& Bridge, CSMSS Dental College \&Hospital, Aurangabad \\ ${ }^{2}$ Post graduate Student, Department of Prosthodontics and Crown \& Bridge, CSMSS Dental College \&Hospital, Aurangabad \\ ${ }^{3}$ MDS, Professor and Head of the Department, Department of Prosthodontics and Crown \& Bridge, \\ CSMSS Dental College \&Hospital, Aurangabad \\ 4 Post graduate Student, Department of Conservative Dentistry and Endodontics. Guru Nanak Institute \\ of Dental Sciences \& Research, Kolkata \\ *Corresponding author E-mail: nikitaparasrampuria@gmail.com
}

\begin{abstract}
The variety of terms used has contributed to a great amount of confusion that exists in this already complicated field of study. Lack of communication and coordination of research efforts often begins with differences in terminology. Therefore in an attempt to coordinate efforts, the American Dental Association began to use TMD to include all functional disturbances of the masticatory system. The article reviews the research work done by various authors pertaining to the disorders of the temporomandibular joint.
\end{abstract}

Keywords: Temporomandibular Joint; Syndrome; Costen; Articular Disk; Capsule; Dislocation; Nocturnal; Bruxism; Condyle

\section{Introduction}

Why the term temporomandibular disorder? The clinical signs and symptoms displayed by masticatory disorders are much too varied to be classified as a "syndrome." According to medical definition, a syndrome is a set of symptoms which occur together; a symptom complex. The term is meant to apply to symptoms as such. A disorder is a derangement or abnormality of function, a morbid physical or mental state. This term applies not to symptoms but to conditions. The general term temporomandibular disorders should designate the conditions that comprise complaints of the masticatory system involving the craniomandibular articulation and its musculature. This term does not suggest merely problems that are isolated to the joints but includes all disturbances associated with the function of the masticatory system.

Over the years functional disturbances of the masticatory system have been identified by a variety of terms. In 1934 James Costen described a group of symptoms that centered on the ear and temporomandibular joint (TMJ). Because of his work the term Costen syndrome developed; later the term temporomandibular joint disturbances became popular. In 1959 Shore introduced the term temporomandibular joint dysfunction syndrome. Later came the term functional temporomandibular joint disturbances, coined by Ash and Ramfjord. Some terms described the suggested causes, such as occlusomandibular disturbance and myoarthropathy of the temporomandibular joint. Others stressed pain, such as pain dysfunction syndrome, myofascial pain dysfunction syndrome, and temporomandibular pain dysfunction syndrome. Because the symptoms are not always isolated to the TMJ, some authors believe that the foregoing terms are too limited and that a broader, collective term should be used, such as craniomandibular disorders. Bell suggested the term temporomandibular disorders (TMDs), which has gained popularity.

\section{The Literature Review for the Temporomandibular Disorders}

Saper [1] (1957) commented that temporomandibular joint pain was psychogenic; Copland observed neuromuscular tension in 74 his patient, which increased in association with examinations, emotional disturbances.

Johan Ulrich [2] (1959) summarized the shape of the joint surfaces do not govern movements, but these are determined rather by the synergistic action of muscles.

Schweitzer JM [3] (1961) conducted a study on masticatory function in man. The study gave a composite picture of the total envelop of motion and the functional envelop and demonstrated the difference between these two envelopes.

In an examination of 200 males in a Veterans administrative hospital, Loiselle [4] (1969) reported that despite many occlusal disharmonies none was considered to have temporomandibular dysfunction. Edentulous persons despite overclosure, rarely have myofacial pain and those who wear dentures with decreased vertical dimension, or other occlusal problems, rarely have temporomandibular joint disturbances.

Laskin and Perry H.T. [5] (1969) introduced the term Myofacial pain dysfunction syndrome and re-emphasized that the disease entity is primarily in the muscle and only secondarily a joint problem. His concept is the Psycho physiologic theory.

Gibbs [6] CH et al. (1971) did a study on the functional movements of the mandible. The study concluded that the presence of a working side condyle is an important constraint which aids in control of closure in the intercuspal range where tooth contacts and resulting forces can occur.

Solberg WK [7] et al. (1972) studied the emotional and occlusal components in temporomandibular joint pain and dysfunction. They concluded that within the scope of the methods used in the study there appear to be no significant differences in occlusion between symptom and control groups. There was no significant 
relationship between anxiety level and dental malocclusion in the symptom group.

Mongini F [8] (1977) evaluated an anatomic and clinical investigation of condylar remodeling, the position of the condyle in centric occlusion and the relationship of these two factors to each other and to the feature of the dentition.

Jose Granados [9] (1979) evaluated whether changes in attrition and loss of teeth would correlate with a change in the articular eminence.

Kopp and Rockier [10] (1979) found that patients with temporomandibular joint crepitation showed a higher frequency of radiologic abnormalities than patients without crepitation.

Catherine D. Campbell [11] and her co-workers (1982) determined the relationship between the temporomandibular joint syndromes and a-history of referred pain patterns.

DE Boevera JA and Adriaens PA [12] (1983) studied the occlusal relationship in patients with pain dysfunction symptoms in the temporomandibular joints.

Williamson and Lundquist [13], (1983) studying the effect of various occlusal contact patterns on the temporal and masseter muscles, reported that when subjects with bilateral occlusal contacts during a laterotrusive excursion were asked to move in that direction, all four muscles remained active. Thus the study substantiates the concept that the occlusal condition can increase muscle activity.

Manns A, Miralles R [14] et al. (1983) conducted a study on the influence of the vertical dimension in the treatment of myofacial pain dysfunction syndrome. They constructed occlusal splints at three different vertical dimensions.

Rieder CE, Martinoffit [15] (1983) studied the prevalence of mandibular dysfunction, age and sex distribution of related signs and symptoms.

Rugh [16] et al. (1984) they deliberately placed a high crown in ten subjects and observed its effects on nocturnal bruxism.

Gibbs CH [17] et al. (1986) conducted a study to test limits of human bite strength. They concluded that human bite strength potential has been underestimated. The bite strength in some bruxers/clenchers can be six times that of a non bruxer.

Barghi N [18] et al. (1987) studied the prevalence of types of temporomandibular joint clicking's in subjects with missing posterior teeth.

Carpentier P [19] (1988) studied the insertion of the lateral pterygoid muscle and demonstrated that the main insertions of the superior head of the lateral pterygoid are not attached to the disc, but to the condyle, and that they fuse together with the fibers of the lower head in front of the TMJ.

Wilkinson TM [20] (1988) dissected 26 human cadaver temporomandibular joints to investigate the superior and inferior heads of the lateral pterygoid muscles and the nature of the attachment of the foot of articular disc to the roof of the superior head of the lateral pterygoid muscle.

Alsawaf M, Garlapo DA [21] et al. (1989) examined the relationship between condylar guidance and temporomandibular joint clicking in 28 subjects

Throckmorton GS [22] et al. (1990) studied muscle activity patterns and temporomandibular joint loads.

Murakami KI [23] (1990), studied "The arthroscopy of the temporomandibular joint (TMJ) as a useful diagnostic manner as well as the alternative surgical procedures in the treatment of TMJ internal derangements.

Wink CS et al. [24] in 1992 demonstrated that the articular disc of human TMJ appears to have a neural network extending from the precapsular connective tissue peripherally into the disc.

Ai M. and Yamashita S [25] (1992) investigated the tenderness of the temporomandibular joint, muscles and their relation to occlusion in patients with temporomandibular joint dysfunction Cohen SG [26] (1994) studied "Internal derangements of the temporomandibular joint (TMJ) that can elicit symptoms of pain, clicking and noises described subjectively as popping, grinding or grating.
Greene CS [27] in 1994 studied the temporomandibular disorders in geriatric population and concluded that overall prevalence of TMD diminishes in the elderly population, but it is not as low as the treatment seeking numbers might suggest.

Zaki HS, Greco CM [28] et al. (1996) conducted a study on "Elongated styloid process in a temporomandibular disorder sample: Prevalence and treatment outcome."

De- Meyer MD, De-Boever JA [29] (1997), studied bruxism both in young and adult population. The symptoms most often associated with bruxism like muscle-stiffness and pain, limitation of mouth opening, TMJ internal derangements are also found in TMD patients.

Mc Neill C [30] (1997) studied management of temporomandibular disorders, the concepts and controversies. This article concludes that a majority of temporomandibular disorder patients achieve good relief of symptoms with noninvasive reversible therapy.

Ito $\mathrm{H}$, Okimoto $\mathrm{K}$ et al. [31] in 1997 studied the relationship between occlusal curvature and craniomandibular disorders.

Kirveskari P, Jamsa T [32] et al. (1998) studied the occlusal adjustment and the incidence of demand for temporomandibular disorder treatment.

Kahn J, Tallents RH [33] et al. (1999) evaluated the prevalence of dental occlusal variables and intraarticular temporomandibular disorders, the molar relationship, lateral guidance, and nonworking side contacts.

Pullinger AG, Seligman DA [34] (2000) conducted a study on quantification and validation of predictive values of occlusal variables in temporomandibular disorders using a multifactorial analysis.

Seligman DA, Pullinger AG [35] (2000) conducted an analysis of occlusal variables, dental attrition, and age for distinguishing healthy controls from female patients with intracapsular temporomandibular disorders.

Stratmann U, Mokrys K [36] et al. (2000) conducted a study on clinical anatomy and palpability of the inferior lateral pterygoid muscle.

Ciancaglini R, Gherlone EF et al. [37] in 2003 conducted a study on unilateral temporomandibular disorder and asymmetry of occlusal contacts.

Anna Pergamalian [38] et al. (2003) did a study to evaluate the association between wear facets, bruxism, and severity of facial pain in patients with temporomandibular disorders.

Hirsch C [39] et al. (2003) did a study to determine if anterior tooth wear is associated with the self-report of TMD pain in children and adolescents.

Allen EP, Bayne SC [40] et al. (2004) they reviewed dental literature published in 2003 and summarized articles selected on the basis of new information or important confirmatory results that contribute to the advance of dentistry.

Nekora-Azak A [41] (2004) this article reviewed the role of female reproductive hormones in TMD as the literature indicated that the overwhelming majority of patients treated for TMD are women.

Edward .P Allen, Alan H. Brodine [42] (2005) reviewed the accepted theory of the multifactorial etiology of TMD that has resulted in a de-emphasis of occlusion as a prime etiologic factor.

Edward P Allen, Alan H Brodine 2006 [43] reviewed the Studies which have demonstrated that the proinflammatory cytokines such as TNF-alpha, IL-6, IL- 1 Beta, as well as cytokine receptors and antagonists influence and participate in the pathogenesis of joint disorders, such as osteoarthritis and rheutmatoid arthritis.

Terence E. Donovan, William Becker [44] (2007) proposed that TMD literature documents the successful reduction of painful symptoms with occlusal device therapy.

Terence E. Donovan, William Becker [45] (2008) said that although the literature suggests that occlusion may be implemented as a risk factor in the development of TMD, this has recently been challenged. 
Terence E. Donovan, William Becker [46] (2010) said that The TMJ undergoes continuous remodeling during active growth in childhood

M. Troeltzsch, A M. Troeltzsch [47] (2011), in their article said that Headache is a widespread ailment. Both temporomandibular joint disorders (TMD) and headache have major impacts on the quality of life.

Sabine S. Linsen, Dr Med Dent [48] (2012) proposed that Recording maxillomandibular relationships is a central aspect of prosthodontics.

Terence E. Donovan, A Maxwell Anderson [49] (2013) said that the, Research into the causes and treatment of TMDs must be based on reliable and valid diagnostic criteria. Imaging the TMJ is one step of the diagnostic sequence in addition to clinical findings. Terence E. Donovan, Ricardo Marzola [50] (2014) reviewed that the blood supply to the TMJ is circumferential. Every vessel within a radius of $3 \mathrm{~cm}$ contributes branches to the joint capsule and contributes one or two branches to it.

Larissa Soares Reis Vilnova [51] (2014) Myofascial pain (MFP) is the most common temporomandibular disorder (TMD) and is characterized by muscle tenderness, local and referred pain on the temporomandibular joint (TMJ) and/or masticatory muscles, and a slightly limited range of jaw motion.

\section{Conclusion}

Temporomandibular joint is a ginglimo diarthrodial joint,consisting of two synovial joint cavities separated by an articular disc. Rotatory movement of the condyle takes place in the lower joint cavity between the disc and the head of the condyle, whereas translatory movement of the condyle occurs in the upper joint compartment between the articular disc and glenoid fossa. The presence of a dense avascular fibro cartilage disc between the condyle and articular fossa is another unique and characteristic feature of this joint, so the load and stress during mandibular function is taken up by the disc and not the fossa. The temporomandibular joint does not function independently, one joint is interdependent on the other. This interdependence makes simple opening movement of the mandible up to $2 \mathrm{~cm}$, there is rotation of the head of the condyle beneath the inferior surface of the disc. Beyond this distance, there is bodily translation of the head of the condyle with the disc moving along with it as one unit. During protrusion the condyles travel forward, one condyle may take a longer translation than the other. During the lateral movement of the mandible while the condyle of one joint moves by inward, downward and forward, a compensating side shift of the opposite condyle takes place to accommodate the medial movement of the downward and forward moving condyle. This movement was described by Bennett, hence it is known as Bennett side shift or "Bennett movement". The temporomandibular joint are guided by the nature of the occlusal surface of the teeth. There exists an occluso articular harmony; any situation which interferes with this harmony may cause T.MJ. dysfunction. A combination of dental and medical therapy is most effective in the treatment of TMJ. Non-surgical treatments such as counselling, pharmacotherapy, and occlusal splint therapy continue to be the most effective way of managing over $80 \%$ of patients. Finally it should be emphasised that the movements of the joint is influenced by neuromuscuiar proprioceptive signals from the periodontal membrane of teeth, musculature and the joint itself. The proprioceptive receptors situated in the periodontal membrane perceive the character of occlusal surface and the nature of food between the teeth; transmits this information to the CNS, which in turn program the muscle function to activate the most physiological mandibular movement to compliment the prevailing occlusal condition. Thus, the final decision of mandibular movement will be programmed to a large extent from the proprioception of periodontal membrane and musculature to initiate a plan of action for the chewing cycle. When pathological occlusion or any form of occiusal disharmony exists the proprioceptive signals initiate a plan of inaction. This is seen in the form of inhibition and deviation of normal mandibuiar movements and spasm of the muscles.

\section{References}

[1] Saper, Schwartz L. Temporomandibular joint syndromes. J. Prosthet Dent 1957; 7:489-494. https://doi.org/10.1016/00223913(57)90055-0.

[2] Ulrich J. The human temporomandibular joint: kinematics and actions of the masticatory muscles.J Prosthet Dent 1959; 9: 399-406. https://doi.org/10.1016/0022-3913(59)90070-8.

[3] Schweitzer JM. Masticatory function in man, J Prosthet Dent 1961; 11: 625- 47. https://doi.org/10.1016/0022-3913(61)90171-8.

[4] Loiselle, Newton A. V. Predisposing causes for temporomandibular joint dysfunction. J. Prosthet Dent 1969; 22: 647-650. https://doi.org/10.1016/S0022-3913(69)80007-7.

[5] Laskin, Perry H. T. The symptomology of temporomandibular joint disturbances. J. Prosthet Dent 1969; 19: 288-293.

[6] Gibbs CH, Messerman T, Reswick JB, Oerda HJ: Functional movements of the mandible, J Prosthet Dent 1971; 26: 604-620. https://doi.org/10.1016/0022-3913(71)90085-0.

[7] Solberg WK, Flint RT, Branter JP. Temporomandibular joint pain and dysfunction: A clinical study of emotional and occlusal components. J Prosthet Dent 1972; 28: 412-422. https://doi.org/10.1016/0022-3913(72)90243-0.

[8] Mongini F. Anatomic and clinical evaluation of the relationship between the temporomandibular joint and occlusion. J Prosthet Dent 1997; 38: 539-551. https://doi.org/10.1016/00223913(77)90030-0.

[9] Jose Granados. The influence of the loss of teeth and attrition on the articular eminence". J Prosthet Dent 1979; 42: 78-85. https://doi.org/10.1016/0022-3913(79)90333-0.

[10] Kopp S, Rockler B. Relationship between clinical and radiographic findings in patients with mandibular pain or dysfunction. Acta Radiol [Diag] (Stockh) 1979; 20: 465 https://doi.org/10.1177/028418517902000309.

[11] Cathrine D, Campbell. Temporomandibular joint symptoms and referred pain patterns. J Prosthet Dent 1982; 47: 430-432. https://doi.org/10.1016/S0022-3913(82)80096-6.

[12] De Boever JA, Adrianens PA. Occlusal relationship in patients with pain dysfunction symptoms in the temporomandibular joints. Joumal of Oral Rehabilitation 1983; 10: 1 . https://doi.org/10.1111/j.1365-2842.1983.tb00093.x.

[13] Williamson EH, Lundquist DO. Anterior guidance: its effect on electromyographic activity of the temporal and masseter muscles. J Prosthet Dent 1983; 49: 816-823. https://doi.org/10.1016/00223913(83)90356-6.

[14] Manns A, Miralles R, Santander H, Valdivia J. Influence of the vertical dimension in the treatment of myofascial pain-dysfunction syndrome. J Prosthet Dent 1983; 50: 700-709. https://doi.org/10.1016/0022-3913(83)90213-5.

[15] Rieder CE, Martinoff IT, Wilcox SA. The prevalence of mandibular dysfunction. Part I: sex and age distribution of related signs and symptoms. J Prosthet Dent 1983; 50: 81-88. https://doi.org/10.1016/0022-3913(83)90171-3.

[16] Rugh JD, Barghi N, Drago CJ. Experimental occlusal discrepancies and nocturnal bruxism. J Prosthet Dent 1984; 51: 548-553. https://doi.org/10.1016/0022-3913(84)90312-3.

[17] Gibbs CH, Mahan PE, Mauderli A, Lundeen HC, Walsh EK. Limits of human bite strength. J Prosthet Dent 1986; 56: 226-229. https://doi.org/10.1016/0022-3913(86)90480-4.

[18] Barghi N, Aguilar T, Martinez C, Woodwall WS, Maaskan BA.Prevalence of types of temporomandibular joint clickings in subjects with missing posterior teeth. J Prosthet Dent 1987; 57 : 617-620. https://doi.org/10.1016/0022-3913(87)90347-7.

[19] Carpentier P, Yung JP, Marguelles-Bonnet R, Meunissier M. Insertion of the lateral pterygoid: an anatomic study of the human temporomandibular joint. J Oral Maxillofacial Surg 1988; 46: 477-782. https://doi.org/10.1016/0278-2391(88)90417-X.

[20] Wilkinson TM. The relationship between the disk and the lateral pterygoid muscle in the human temporomandibular joint.J Prosthet Dent 1988; 60: 715724. https://doi.org/10.1016/00223913(88)90406-4.

[21] Alsawaf M, Garlapo DA, Gale EN, Carter MJ.The relationship between condylar guidance and temporomandibular joint clicking. J Prosthet Dent 1989; 61: 349. https://doi.org/10.1016/00223913(89)90144-3. 
[22] Throckmorton GS, Groshan GJ, Boyd SB.Muscle activity patterns and control of temporomandibular joint loads, J Prosthet Dent 1990; 63: 685-695. https://doi.org/10.1016/0022-3913(90)90327-9.

[23] Murakami KI. The indications of arthoscopic sweep for the patient with internal derangements of the temporomandibular joint .Rev Stomatol Chir-Maxillofac, 1990; 91(2):110-9.

[24] Wink CS, Onge M, Zimny ML.Neural elements in the human temporomandibular articular disc. J Oral Maxillofacial Surg 1992; 50: 334-337. https://doi.org/10.1016/0278-2391(92)90391-C.

[25] Ai M, Yamashita S.Tenderness of palpation and occlusal abnormalities in temporomandibular joint dysfunction. J Prosthet Dent 1992; 67: 839-845. https://doi.org/10.1016/0022-3913(92)90597-4.

[26] Cohen SG.The use of magnetic resonance imaging to determine splint position in the management of internal derangements of the temporomandibular joint. Cranio, 1994; 12(3):167-71. https://doi.org/10.1080/08869634.1994.11678014.

[27] Greene CS. Temporomandibular disorders in the geriatric population. J Prosthet Dent 1994; 72: 507-509. https://doi.org/10.1016/0022-3913(94)90123-6.

[28] Zaki HS, Greco CM, Rudy TE, Kubinski IA. Elongated styloid process in a temporomandibular disorder sample: prevalence and treatment outcome.J Prosthet Dent 1996; 75: 399-405. https://doi.org/10.1016/S0022-3913(96)90032-3.

[29] De-Meyer MD, De-Boever JA. The role of bruxism in the appearance of temporomandibular joint disorders. Rev-Belge-Med-Dent. 1997; 52 (4):124-38

[30] McNeill C. Management of temporomandibular disorders: Concepts and controversies. J Prosthet Dent 1997; 77: 510-22. https://doi.org/10.1016/S0022-3913(97)70145-8.

[31] Ito H, Okimoto K, Terada Y, Mizumori T, MaruyamaT. A clinical study of the relationship between occlusal curvature and craniomandibular disorders. Int J Prosthodont 1997; 10: 78-82.

[32] Kirveskari P, Jamsa T, Alanen P. Occlusal adjustment and the incidence of demand for temporomandibular disorder treatment. J Prosthet Dent 1998; 79: 433-438. https://doi.org/10.1016/S00223913(98)70158-1.

[33] Kahn J, Tallents RH, Katzberg RW, Ross ME, Murphy WC. Prevalence of dental occlusal variables and intraarticular temporomandibular disorders: molar relationship, lateral guidance, and nonworking side contacts. J Prosthet Dent 1999; 82: 410-415. https://doi.org/10.1016/S0022-3913(99)70027-2.

[34] Pullinger AG, Seligman DA. Quantification and validation of predictive values of occlusal variables in temporomandibular disorders using a multifactorial analysis. J Prosthet Dent 2000; 83: 66-75. https://doi.org/10.1016/S0022-3913(00)70090-4.

[35] Seligman DA, Pullinger AG. Analysis of occlusal variables, denta attrition, and age for distinguishing healthy controls from female patients with intra capsular temporomandibular disorders.J Prosthet Dent 2000; 83: 76-82. https://doi.org/10.1016/S00223913(00)70091-6.

[36] Stratmann U, Mokrys K, Meyer U, Kleinheinz J, Joos U.Clinical anatomy and palpability of the inferior lateral pterygoid muscle.J Prosthet Dent 2000; 83: 548-554. https://doi.org/10.1016/S00223913(00)70013-8

[37] Ciancaglini R, Gherlone EF. Unilateral temporomandibular disorder and asymmetry of occlusal contacts. J Prosthet Dent 2003; 89 : 180-5. https://doi.org/10.1067/mpr.2003.9.

[38] Anna Pergamalian, Thomas E. Rudy, Hussein S. Zaki, Carol M Greco. The association between wear facets, bruxism, and severity of facial pain in patients with temporomandibular disorders. J Prosthet Dent 2003; 90: 194. https://doi.org/10.1016/S00223913(03)00332-9.

[39] Hirsch C, John MT, Lobbezoo F, Setz JM, Hans-Guenter Schaller Incisal tooth wear and self-reported TMD pain in children and adolescence. Int J Prosthodont 2004; 17(2): 205-210.

[40] Allen EP, Bayne SC, Cronin Jr RJ, Donovan TE, Kois JC, Summit JB. Annual review of selected dental literature: report of the committee on scientific investigation of the American academy of restorative dentistry. J Prosthet Dent 2004; 92: 39-71. https://doi.org/10.1016/j.prosdent.2004.04.015.

[41] Nekora-Azak A. Temporomandibular disorders in relation to female reproductive hormones: A literature review. J Prosthet Dent 2004; 91: 491-493. https://doi.org/10.1016/j.prosdent.2004.03.002.

[42] Edward P Allen, Alan H. Brodine. Annual review of selected denta literature: report of the committee on scientific investigation of the American academy of restorative dentistry. J Prosthet Dent 2005; 94: 146-176. https://doi.org/10.1016/j.prosdent.2005.05.003.

[43] Edward P Allen, Alan H. Brodine. Annual review of selected denta literature: report of the committee on scientific investigation of the
American academy of restorative dentistry. J Prosthet Dent 2006; 96: 174-199. https://doi.org/10.1016/j.prosdent.2006.07.006

[44] Terence E. Donovan, William Becker, Alan H Brodine,John O. Burgess, Robert J. Cronin, and James B. Summitt, Annual review of selected dental literature: report of the committee on scientific investigation of the American academy of restorative dentistry. J Prosthet Dent, 2007; 98:36-67. https://doi.org/10.1016/S0022 3913(07)60036-5.

[45] Terence E. Donovan,William Becker, Alan H. Brodine,John O. Burgess, David R.and James B. Summitt, Annual review of selected dental literature: report of the committee on scientific investigation of the American academy of restorative dentistry. J Prosthet Dent 2008; 100: 110-141. https://doi.org/10.1016/S00223913(08)60159-6.

[46] Terence E. Donovan, William Becker, David R. Cagna, Thomas J. Hilton and Jeffrey Rouse, Annual review of selected dental literature: report of the committee on scientific investigation of the American academy of restorative dentistry. J Prosthet Dent 2010; 104: 13-47. https://doi.org/10.1016/S0022-3913(10)60087-X.

[47] M. Troeltzsch, R.J. Cronin, A.H. Brodine, Frankenberger and K. Messlinger, Prevalence and association of headaches, temporomandibular joint disorders, and occlusal interferences, J Prosthet Dent 2011;105:410-417. https://doi.org/10.1016/S0022-3913(11)60084$\underline{X}$

[48] Sabine S. Linsen, Helmut Stark and Azadeh Samaic, The influence of different registration techniques on condyle displacement and electromyographic activity in stomatognathically healthy subjects: A prospective study, J Prosthet Dent 2012; 107: 47-52. https://doi.org/10.1016/S0022-3913(12)60017-1.

[49] Terence E. Donovan, Maxwell Anderson,William Becker,David R. Cagna,Gary B. Carr, Jean-Pierre Albouy,James Metz,Fred Eichmiller, and James R. McKee, Annual review of selected dental literature: report of the committee on scientific investigation of the American academy of restorative dentistry, J Prosthet Dent 2013;110:161-210. https://doi.org/10.1016/S0022-3913(13)60358-3.

[50] Terence E. Donovan,Riccardo Marzola, William Becker,David R. Cagna , Annual review of selected dental literature: report of the committee on scientific investigation of the American academy of restorative dentistry, J Prosthet Dent 2014;112:1038-1087. https://doi.org/10.1016/j.prosdent.2014.09.001.

[51] Larissa Soares Reis Vilnova, Mastication movements and sleep quality of patients with myofascial pain: Occlusal Device therapy Improvements, J Prosthet Dent 2014; 112: 1330-1336. https://doi.org/10.1016/j.prosdent.2014.07.008. 